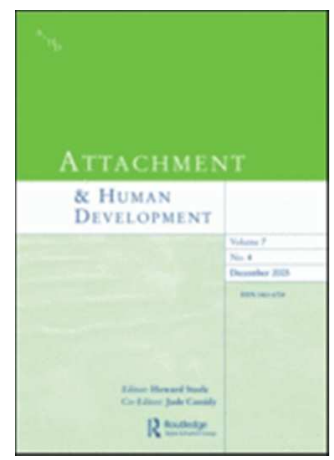

\title{
Parental Reflective Functioning and Executive Functioning in Mothers with Substance Use Disorder
}

\begin{tabular}{|r|l|}
\hline Journal: & Attachment \& Human Development \\
\hline Manuscript ID & RAHD-2017-0045.R4 \\
\hline Manuscript Type: & Original Research Paper \\
\hline Keywords: & $\begin{array}{l}\text { Parental Reflective Functioning, Maternal, Executive Functioning, Substance } \\
\text { Use Disorder, Psychological Distress }\end{array}$ \\
\hline \multicolumn{2}{|l}{} \\
\hline
\end{tabular}

SCHOLARONE

Manuscripts 
Parental Reflective Functioning and Executive Functioning in Mothers with Substance Use Disorder

\section{Parental Reflective Functioning and Executive Functioning in Mothers with Substance Use Disorder} Ulrika Håkansson ${ }^{1}$, Kerstin Söderström $^{1,2}$, Reidulf Watten ${ }^{1}$, Finn Skårderud ${ }^{3}$, Merete Glenne
Øie $^{4,5}$

${ }^{1}$ Innland Norway University of Applied Sciences, Norway. ${ }^{2}$ Division Mental Health Care, Innlandet Hospital Trust, Norway. ${ }^{3}$ Norwegian School of Sport Science, University of Oslo, Norway. ${ }^{4}$ Department of Psychology, University of Oslo, Oslo, Norway. ${ }^{5}$ Research Division, Innlandet Hospital Trust, Lillehammer, Norway.

Corresponding author, Ulrika Håkansson. ulrika.hakansson@inn.no

\section{Competing interests}

The authors declare they have no competing interests.

\section{Acknowledgment}

The project received financial support from The Research Council of Norway (NFR), grant number 213079/H10. We would like to thank Innlandet Hospital Trust and Innland Norway University of Applied Sciences for their technical and academic support. We especially want to thank the parents and children who participated in the project. We also appreciate the collaboration with numerous clinicians, both in therapeutic clinics and in municipalities for their contribution to the study. In addition, we would like to thank two anonymous reviewers for valuable comments on an earlier version on this paper. 


\begin{abstract}
Having a substance use disorder (SUD) may adversely affect caregiving capacities. Reflective functioning (RF) and executive functioning (EF) are both important capacities for sensitive parenting, and are often impaired in a SUD. Only a few studies have explored the possible association between the two phenomena. In this study, we used a neuropsychological test battery to assess EF, and the Parent Development Interview to assess RF in a sample of mothers with a SUD $(N=43)$. Although parental RF (PRF) was associated with EF, when controlled for intelligence (IQ) and mental health, there was no significant association between EF and PRF. Mental health, however, showed a significant negative association with PRF. Splitting the group in two based on PRF level, mothers with a negative to low PRF exhibited more severe difficulties in SUD-related aspects, as well as in several EF components, compared to mothers with an adequate to high PRF, highlighting the association between EF and PRF. The results from this study contribute to enhance our understanding of the dynamics underlying vulnerability in PRF that mothers with small children may experience. We suggest EF to be a prerequisite for adequate PRF, and for interventions to be customized accordingly regarding parents with a SUD.
\end{abstract}

Keywords: parental reflective functioning, infant, maternal, executive functioning, substance use disorder 
Parental Reflective Functioning and Executive Functioning in Mothers with Substance Use Disorder

\section{Introduction}

Several studies have shown that as a group, mothers with a substance use disorder (SUD) are at risk of maladaptive parenting practices (Cash \& Wilke, 2003; Mayes \& Truman, 2002; Walsh, MacMillan, \& Jamieson, 2003) and associated with an increased risk of child neglect and abuse (Pajulo, Suchman, Kalland, \& Mayes, 2006). Maternal SUD poses a threat to the quality of sensitive parenting (Siqveland, Smith, \& Moe, 2012). A sensitive caregiving environment is proposed to be essential for a healthy development of the infant brain and biological system, and consequently the development of physical, social, emotional and cognitive capacities in the child (Atkinson, Leung, Goldberg, Benoit, Poulton et al., 2009; Shonkoff, Garner, Siegel, Dobbins, Earls et al., 2012).

Mentalization is a fundamental part of sensitive caregiving (Slade, 2005), which involves the ability to understand others and oneself in terms of feelings, wishes and thoughts, in addition to the capacity to interpret mental states underlying behavioural expressions (Fonagy \& Target, 1997). Although there is some support for a moderate relationship between mentalizing and intelligence (IQ) (Capstick, 2008; Steele \& Steele, 2008), as well as between IQ and embodied mentalizing (Shai \& Belsky, 2017), others have not found such a relationship (Grienenberger \& Slade, 2002). Reflective functioning (RF) is the manifestation of the capacity to mentalize, although the terms are often used interchangeably (Suchman, Ordway, de las Heras, \& McMahon, 2016). RF is an innate human characteristic (Kovács, Téglás, \& Endress, 2010), though it is continuously influenced by environmental experiences (Fonagy, Target, Gergely, Allen, \& Bateman, 2003), and has been associated with mental health issues (Bouchard, Target, Lecours, Fonagy, Tremblay et al., 2008; Fischer-Kern, Fonagy, Kapusta, Luyten, Boss et al., 2013). 
Parental reflective functioning (PRF) refers to a mentalizing capacity in relation to one's child, including the caregiver's capacity to recognize the child's expression and behaviour as being linked to the inner world of mental states, and as being influenced by the parents' own mental state (Slade, 2005). As a group, mothers with a SUD are often reported to have impairments in PRF, although with individual variations (Pajulo et al., 2006; Suchman, McMahon, Slade, \& Luthar, 2005).

PRF can be distinguished between being average too high or negative to low, in which the latter is related to not fully realized reflective capacities (Kelly, Slade, \& Grienenberger, 2005; Taubner, Horz, Fischer-Kern, Doering, Buchheim et al., 2013). Mothers with a negative to low PRF have been found to have difficulties in recognizing and processing their own and their infant's emotions, which could result in distorted reflections concerning their own parenting abilities and the infant's capabilities (Luthar \& Suchman, 2000). Accordingly, there is a risk of disruptions in the dyadic communication between mother and infant, which heightens the risk of insensitive maternal behaviour such as disengagement, withdrawal, hostility and intrusiveness (Kelly et al., 2005; Levy \& Truman, 2002). Vulnerability in PRF is associated with poorer psychosocial infant development (Levy, Truman, \& Mayes, 2001; Lyons-Ruth, Bronfman, \& Atwood, 1999). PRF is also associated with both adequate and inadequate parenting behaviour (Levy \& Truman, 2002), including neglect and abuse (Fonagy, Steele, Steele, Leigh, Kennedy et al., 1995). Parenting interventions targeted towards PRF in SUD mothers are associated with an improvement in caregiving capacities (Suchman, DeCoste, Castiglioni, Legow, \& Mayes, 2008).

Maternal sensitivity also involves executive functions (EF). EF are a multidimensional construct involving a number of cognitive processes, such as inhibition, working memory, cognitive flexibility, planning and regulation of attention and emotion (Pennington 
Parental Reflective Functioning and Executive Functioning in Mothers with Substance Use Disorder

\& Ozonoff, 1996). EF are thought to be a higher level cognitive functioning involved in the control and regulation of lower level functioning such as emotional and behavioural processes (Miller \& Cohen, 2001). Even though EF are related to intelligence (IQ) (Friedman \& Miyake, 2017), there is a diversity in how IQ relates to different EF components. One study has shown that working memory is associated with IQ, but inhibition and cognitive flexibility are not (Friedman, Miyake, Corley, Young, DeFries et al., 2006).

Disruptions in a number of EF components are frequently described in addiction research (Kalivas \& Volkow, 2005). In addition, executive dysfunction can be a risk marker for SUD (Dolan, Bechara, \& Nathan, 2008). Substance use is also associated with neural abnormalities in the frontal lobes, and accordingly linked to alterations in EF (Bechara, Dolan, Denburg, Hindes, Anderson et al., 2001; Moreno-López, Stamatakis, FernándezSerrano, Gómez-Río, Rodríguez-Fernández et al., 2012).

High EF are associated with perceptive, responsive and flexible parenting behaviour (Galinsky, 2010; Kienhuis, Rogers, Giallo, Matthews, \& Treyvaud, 2010), including supportive responses to children's emotions (Hughes \& Gullone, 2010; Valiente, Lemery $\square$ Chalfant, \& Reiser, 2007), as well as parental sensitivity and warmth (Chico, Gonzalez, Ali, Steiner, \& Fleming, 2014; Gonzalez, Jenkins, Steiner, \& Fleming, 2012). Mothers with low $\mathrm{EF}$ are less able to manage intense emotions and tend to dysregulate in response to parental stress (Skowron \& Friedlander, 1998), in addition to expressing less positive parenting behaviour (Deater-Deckard, Sewell, Petrill, \& Thompson, 2010). Furthermore, weaknesses in EF are known to be related to psychological distress and mental health issues (Dvir, Ford, Hill, \& Frazier, 2014; Gonzalez, 2015; Gonzalez, Atkinson, \& Fleming, 2009; Leyro, Zvolensky, \& Bernstein, 2010). In addition, for individuals with a previous SUD, even if there may be an improvement in EF during substance abstinence, some deficits in EF are still 
Parental Reflective Functioning and Executive Functioning in Mothers with Substance Use Disorder

present, despite the actual abuse being terminated (Verdejo-García, Bechara, Recknor, \& Perez-Garcia, 2006). This implies that the etiological explanation for EF difficulties may be a consequence of a SUD (Giancola \& Tarter, 1999), or they may originate before the onset of the actual addiction. Accordingly, EF difficulties in parenting practices might still exist, even when the use of substances is no longer present.

In summary, although they are distinct capacities, PRF and EF are both essential in sensitive caregiving (Barrett \& Fleming, 2011; Slade, Belsky, Aber, \& Phelps, 1999) and both capacities are found to be impaired in individuals with a SUD (Giancola \& Tarter, 1999; Suchman et al., 2005). Understanding the possible relationship between PRF and EF is important, as it may have implications for the dynamic underlying difficulties in parenting capabilities in SUD mothers.

To the best of our knowledge, only two previous studies have explored the possible association between maternal $\mathrm{RF}$ and $\mathrm{EF}$, and no significant correlations between the two phenomena were found when studying a group of mothers with small children in a nonclinical population (Turner, Wittkowski, \& Hare, 2008). In a similar study examining urban mothers with 9- to 12-year-old children, no associations were found between EF and PRF, even after controlling for lifetime histories of depression and substance abuse (Capstick, 2008). However, several studies have identified associations between EF and a phenomenon closely related to RF, Theory of Mind (ToM) which might help to shed light on the possible relationship between EF and RF. ToM refers to the ability to comprehend and interpret thinking and feeling in another person as intentions (Frith \& Frith, 2003; Premack \& Woodruff, 1978). Although similar and often used interchangeably, there are important differences between RF and ToM. ToM refers to cognitive-perceptual "cold" knowledge of mind, whereas the ability to mentalize (i.e. RF) additionally requires the activation of 
Parental Reflective Functioning and Executive Functioning in Mothers with Substance Use Disorder

relational and emotional "hot” representations (Górska \& Marszał, 2014; Kalbe, Grabenhorst, Brand, Kessler, Hilker et al., 2007). A positive association between ToM and EF has been found in non-clinical populations of children (Austin, Groppe, \& Elsner, 2014; Carlson, Claxton, \& Moses, 2015), adolescents (Vetter, Altgassen, Phillips, Mahy, \& Kliegel, 2013) and adults (Apperly, Samson, \& Humphreys, 2009; Bull, Phillips, \& Conway, 2008), showing that a well-functioning EF system is related to an effective ToM.

Several clinical studies have demonstrated a relationship between deficits in ToM and deficits in EF. An association between ToM and EF has been shown in autism disorders (Baron-Cohen, 1995; Fisher \& Happé, 2005), maternal mental illness (Rigby, Conroy, MieleNorton, Pawlby, \& Happé, 2016) and in SUD populations (Sanvicente-Vieira, RomaniSponchiado, Kluwe-Schiavon, Brietzke, Araujo et al., 2017; Verdejo-Garcia, LópezTorrecillas, de Arcos, \& Pérez-Garcia, 2005). Although there are few studies that have explored the explicit relationship between RF and EF, several studies make implicit inferences of possible associations, which lead us to suggest a relationship between the capacities. For example, a low capacity of self- and other-reflections (i.e. RF) is associated with deficits in affect regulation and flexibility (i.e. EF) in mothers with a SUD (Suchman, Pajulo, DeCoste, \& Mayes, 2006). Furthermore, abilities in affect regulation (i.e. EF), and maternal stress tolerance (Rutherford, Booth, Luyten, Bridgett, \& Mayes, 2015) are associated with stability, flexibility and deficits in RF (Fonagy, Gergely, \& Jurist, 2004). Also, neurological studies have found that the dorsolateral prefrontal cortex is important for EF (Oldrati, Patricelli, Colombo, \& Antonietti, 2016), as well as being the neural circuit partly responsible for mentalizing (Abu-Akel \& Shamay-Tsoory, 2011). These studies makes further investigation of the possible explicit association between PRF and EF in mothers with a SUD relevant. 
Parental Reflective Functioning and Executive Functioning in Mothers with Substance Use Disorder

\section{The current study}

The study consisted of two parts. In the first part, we used a correlational design to examine associations between EF and PRF in mothers with a SUD caring for small children, controlling for IQ and psychological distress. In Part 2, we split the group of mothers, and investigated whether there were differences in SUD-related factors and EF, depending on the PRF level being negative to low or adequate to high. IQ and psychological distress were included as control variables.

Part 1 - We expected that EF and PRF, respectively, would gain low scores in the population of mothers in this study compared to average scores in a normal population. We based this assumption on previous studies that found these two capacities particularly affected by SUD (Deater-Deckard, 2014; Gonzalez, 2015; Suchman, Decoste, Leigh, \& Borelli, 2010). We expected to find positive correlations between PRF and EF. Based on literature concerning the relationship between SUD and EF, we predicted working memory, inhibition, cognitive flexibility, planning and fluency all to be related to low PRF (Bechara, 2005; Fernández-Serrano, Pérez-García, Perales, \& Verdejo-García, 2010; Graham, 2004; Mintzer \& Stitzer, 2002; Valls-Serrano, Verdejo-García, \& Caracuel, 2016; Verdejo-García \& PérezGarcía, 2007; Vik, Cellucci, Jarchow, \& Hedt, 2004). In addition, we expected IQ moderately to affect the relationship between EF and PRF (Steele et al., 2008). Based on earlier studies on emotion regulation (Rutherford et al., 2015), we also expected the level of experienced psychological distress to affect the relationship between PRF and EF.

Part 2 - In the second part of the study, we separated the group of mothers in two, based on PRF level. We expected to find differences depending on the mother exhibiting either a negative to low PRF or an adequate to high PRF. We hypothesized that preference for a specific type of substance would be associated with PRF level. We expected that mothers 
Parental Reflective Functioning and Executive Functioning in Mothers with Substance Use Disorder

preferring stimulants or opioids would exhibit a lower PRF than to mothers preferring alcohol or cannabis. We based these expectations on studies showing that the severity of substance abuse is associated with PRF level (Pajulo, Pyykkönen, Kalland, Sinkkonen, Helenius et al., 2012), and an assumption that an abuse of stimulants and opioids might reflect a more definite substantial substance abuse problem, while an abuse of alcohol and cannabis may be more diverse in its severity. We also anticipated that PRF level would be related to differences in the onset of substance use, as well as onset of the SUD. We based our hypothesis on our own expectation of an association between PRF and EF and previous research showing substance use onset-age to be related to severity in EF difficulties (Gruber, Sagar, Dahlgren, Racine, \& Lukas, 2012), as well as a severity in SUD (Grant \& Dawson, 1998). We expected mothers with a negative to low PRF to have an earlier onset of substance use, as well as an onset of SUD, compared to mothers with an average to high PRF. Moreover, we hypothesized that mothers with a negative to low PRF would exhibit more severe deficits in EF compared to mothers with an average to high PRF.

\section{Methods}

\section{Participants}

Forty-three mothers $(M$ age $=31$ years, $\mathrm{SD}=6.4$ years, range 19 to 44$)$ with a SUD were recruited during pregnancy or during the postpartum period. Twelve of the mothers $(27.9 \%)$ were recruited from outpatient clinics, six $(14.0 \%)$ from municipality health nurses and $25(58.1 \%)$ from one of seven treatment facilities specialized in caring for pregnant women and families with small children and substance abuse problems. The recruitment period lasted for two years. The inclusion criteria were a SUD diagnosis of any severity and 
kind, whether with or without a comorbid mental illness. All the mothers were abstinent during the assessment period, but had previously been diagnosed with a SUD based on the ICD-10 classification of mental and behavioral disorders (World Health Organization, 1993). The diagnoses were confirmed by our assessments. The exclusion criteria were a full IQ below 70, multi-parity, premature birth $(<32$ weeks and $<1500 \mathrm{~g})$, or a severely ill or multihandicapped child, whereas children with neonatal abstinence syndrome (NAS) were not excluded. For the majority of the mothers $(N=27)$, the target child was their first child. Although 16 of the mothers (37.2\%) had older children, only one (2.3\%) had custody of the older sibling of the target child. Siblings were either living in foster care or with their father. At assessment, the age of the target child ranged from four to 18 months $(M=8.6, \mathrm{SD}=$ 3.8). There were 15 girls (34.9\%), and 28 boys (65.1\%). Eleven $(25.6 \%)$ of the children were born with NAS and received medical intervention. During the inclusion period, 12 of the mothers $(27.9 \%)$ lost daily custody of the target child.

Socio-demographic background variables. On average, participants were educated for 11.5 years (range seven to 18 years). Two participants (4.7\%) did not complete primary school, and $22(51.2 \%)$ started but did not complete high school. Six participants $(14.0 \%)$ had a graduate or professional degree beyond high school. Twenty-two mothers $(51.2 \%)$ did not have a partner and $13(30.2 \%)$ had a cohabitant. One participant $(2.3 \%)$ was married and seven $(16.3 \%)$ had a partner who was not a cohabitant. Twenty-four mothers $(55.8 \%)$ reported that the father of the child had an on going substance abuse problem, and 15 (34.9\%) reported a previous, but currently abstinent substance abuse problem in the father. Four mothers (9.3\%) reported that the father never had a substance abuse problem.

\section{Measures}


Socio-demographic variables and use of psychoactive substances - Substance use was registered with the European Addiction Severity Index (Europ-ASI) $5^{\text {th }}$ edition (Kokkevi \& Hartgers, 1995; McLellan, Kushner, Metzger, Peters, Smith et al., 1992), Norwegian version (Lauritzen, 2010). Europ-ASI is a semi-structured clinical interview, which consists of questions related to employment and support status, family and social relationships and legal and illegal substance use, as well as somatic and psychological issues. Reliability and validity for the Europ-ASI has been reported to be satisfactory (Kessler, Cacciola, Alterman, Faller, Souza-Formigoni et al., 2012; Kokkevi \& Hartgers, 1995; McLellan et al., 1992).

Parental Reflective Function (PRF) - To assess PRF, we used the Parent Development Interview-Revised (PDI-R2) (Fonagy, Target, Steele, \& Steele, 1998; Slade, Aber, Berger, Bresgi, Kaplan et al., 2003), Norwegian translation. PDI-R2 is a 20-question semi-structured interview designed to elicit narratives of parental representations. The interview addresses various themes concerning feelings, thoughts and intentions, both in the mother herself and in her child. The interview focuses on how these aspects might influence behaviour and mental processes in the person reflected upon (i.e. oneself or one's child). The PDI-R2 interview was recorded and transcribed from audio files, and the transcribed interviews were coded in accordance with guidelines for RF assessment (Fonagy et al., 1998) by an independent reliable coder who was not familiar with the respondents. A second independent rater coded $25 \%$ of the interviews for reliability purposes. There was a strong intra-class correlation between the coders $(r=.96$. $)$ When there was a disagreement between the coders, we used the assessment from the first coder. The interviews were scored for PRF on an 11-point scale from -1 to 9, with higher scores reflecting a higher RF (Slade, Bernbach, Grienenberger, Levy, \& Locker, 2005). A score of -1 indicates a negative RF and includes a violation of coherence (bizarre) or openly hostile responses. A score of 9 indicates an exceptional RF with 
rich and full reflections. Although scores of 5 or above indicate a clear RF and evidence of mentalizing capacities in a normal population (Slade, 2005), in a stressed or vulnerable population, a score of 4 would constitute the average capacity (Kelly et al., 2005; Levy et al., 2001; Taubner et al., 2013). Therefore, a distinction between a negative to low PRF and an average to high PRF was set at a score of 4 in our sample. Validity for the PDI-RF is reported as being satisfactory in non-clinical populations and in populations of parents with a SUD (Levy \& Truman, 2002; Slade, 2005; Slade et al., 1999).

Executive Functions (EF) - Neuropsychological measures of maternal EF included an assessment of several executive sub-functions. The raw scores were converted into t-scores. We assessed the following EF components:

Working memory - The Letter-Number Sequencing sub-test from the Wechsler Adult Intelligence Scale $4^{\text {th }}$ Edition (Wechsler, 2014) was used. During this task, the participants were presented with an increasingly longer series of mixed letters and numbers at one-second intervals. The participants were required to repeat the series back to the administrator in a manner in which the numbers were presented first in order from the lowest to the highest, followed by the letters in alphabetical order. Higher raw t-scores and longer spans are consistent with a high capacity of auditory working memory.

Verbal Fluency - Two categories from the Verbal Fluency test from the Delis-Kaplan Executive Function System (D-KEFS) (Delis, Kaplan, \& Kramer, 2001), Letter Fluency and Category Fluency were used to assess verbal fluency. Completion of the Letter Fluency condition required participants to say as many words as possible that started with a specific letter within in a 60 -second time frame, which was done with the letters "F", "A" and "S". The participants were instructed that they could not use the names of people, places or numbers, and were only allowed to use each response once. Completion of the Category 
Fluency condition required participants to first say as many animals as possible in a 60second time frame, and then as many boys' names as possible. Higher t-scores on these tasks are indicative of high levels of verbal fluency.

Cognitive inhibition - The Colour-Word Interference Test, Condition 3 from the DKEFS (Delis et al., 2001) was used to assess cognitive inhibition. Participants had to inhibit themselves from reading a colour word, and instead say the name of the colour in which the word was printed as quickly as possible. A longer time to complete the task, as well as a higher frequency of errors, indicated more difficulties with inhibition and provided a lower tscore.

Cognitive flexibility - The inhibition-switching task in the Colour-Word Interference Test, Condition 4 from the D-KEFS (Delis et al., 2001) was used to assess cognitive flexibility. Participants were required to switch between reading the colour word and naming the colour in which the colour was printed. The time used and the numbers of errors committed during the task were measured. A longer time to complete the task, in addition to having more errors, indicated difficulties with cognitive flexibility and provided a lower $\mathrm{t}$ score.

Planning - The Tower Test (Delis et al., 2001) measures planning, rule learning and the ability to establish and maintain an instructional set. Participants were requested to place discs of varying sizes on a board with three vertical pegs in the same manner shown on a picture in front of them as effectively as possible, both regarding the number of movements and time usage. There is an increasing complexity of the test as it progresses from starting with two discs and ending with five discs. Taking a longer time to complete the task, as well as a high frequency of errors, indicated difficulties in planning and yielded a lower t-score. 
Intelligence - .The Wechsler Abbreviated Scale of Intelligence (WASI) (Wechsler, 1999, 2014) measured the participants average estimated full scale IQ, verbal IQ and nonverbal IQ scores.

Mental health - To assess mental illness, we used the diagnostic interview M.I.N.I plus version 5.0.0, Norwegian version (M.I.N.I) (Mordal, Gundersen, \& Bramness, 2010). The instrument is a diagnostic interview related to the diagnostic criteria in DSM-IV (Association, 2000) and ICD-10 (World Health Organization, 1993). M.I.N.I constitutes of 16 modules, and covers 27 psychiatric diagnoses. The instrument has a high inter-rater and testreliability (Rush, First, \& Blacker, 2008).

We used the Hopkins Symptom Checklist (HSCL-10) to measure general mental health status. HSCL-10 is a self-administered questionnaire designed to measure symptoms of anxiety and depression. HSCL-10 is a shortened version of the HSCL-90 (Derogatis, Lipman, Rickels, Uhlenhuth, \& Covi, 1974), and has satisfactory validity and reliability (Haavet, Sirpal, Haugen, \& Christensen, 2010; Strand, Dalgard, Tambs, \& Rognerud, 2003). The HSCL-10 consists of 10 items, in which responses ranges from $1=$ not at all to $4=$ very much. The average item score is calculated by dividing the total score of the number of items answered, the cut-off score of 1.85 is considered to indicate psychological distress (Strand et al., 2003).

\section{Procedures}

We examined the participants at their home or in the treatment facility where they were currently living. Participants were interviewed with Europ-ASI and M.I.N.I plus to establish and/or confirm SUD diagnoses and mental health diagnoses according to ICD-10 (World Health Organization, 1993). The mothers answered the HSCL-10 questionnaire to 
indicate the presence of psychological distress. They were interviewed with the PDI-R2 and also completed the neuropsychological assessments. It should also be mentioned that we collected data from a large battery of measures, and only selected results are presented in this paper. The estimated time for data collection using the larger test-battery was approximately seven hours per family, and each participant met with the researcher on three to six separate occasions to complete the assessment. Each session lasted between one to two hours. A clinical psychologist (UH) supervised by a specialist in clinical neuropsychology (MØ) collected all data, with the data collection for this particular part of the test battery lasting for approximately four hours per respondent.

\section{Ethics}

The study was approved by The Norwegian Regional Committee for Medical Research Ethics in Eastern Norway (REK-Ost), and was conducted in accordance with the Helsinki Declaration of the World Medical Assembly.

\section{Statistical analyses}

All cases $(N=43)$ were included in the analyses and there was no missing data. In Part 1 of the study, we used descriptive statistics of socio-demographic variables, substance use, PRF and EF. In addition, we calculated Pearson product moment correlations between PRF and EF for the total sample. We also conducted a Principal Component Analysis (PCA), on the EF measures and calculated the factor scores of the extracted dimensions. The criteria for the number of factors extracted were set at Eigenvalues $>1$. One major factor was extracted accounting for $56.9 \%$ of the unrotated variance (Eigenvalue $=3.4$ ). The factor loadings of the six EF components were the following: inhibition: .87; working memory: .86; cognitive flexibility: .80; planning: .79; category fluency: .57; and letter fluency: .57. To further inspect 
the links between PRF and EF, we carried out a hierarchical ordinary least square regression analysis, using PRF as the criterion variable, the EF-factor score as predictor variable and total IQ and mental health (HSCL-10) as control variables. Control variables and the predictor variable were entered in two blocks: The first block consisted of the control variables total IQ and HSCL-10. The second block consisted of the EF-factor score. This analytic strategy allowed us to see how much additional variance in PRF the EF-factor accounted for after controlling for IQ and mental health.

In Part 2 of the study, analyses were carried out to test the differences between two groups of mothers differentiated based on exhibiting an adequate to high PRF or exhibiting a negative to low PRF. We used Chi-Square analyses to test differences in reported preference of particular substances, as well as differences in report of multiple substance use in mothers with negative to low PRF and mothers with adequate to high PRF. We conducted a multiple analysis of variance (MANOVA) to test onset-age of substance use, onset-age of SUD and EF, controlling for total IQ and mental health status. All statistical analyses we carried out using IBM Statistical Package for Social Sciences (SPSS) version 24.

\section{Results}

\section{Results Part 1}

\section{Characteristics of the respondents}

Specifications for substance use, outcomes for general PRF and the results of cognitive tests, IQ tests and variables for mental health are presented in Table 1:

Insert Table 1 about here 
As seen in Table 1 , although $86 \%$ of mothers $(n=37)$ reported multi-substance use, all of the respondents could define a preferred substance. The most commonly preferred substances among the mothers were central stimulants and opioids. Twenty-two mothers (51\%) reported injecting substances intravenously, thereby indicating a substantial substance use problem in the group. The majority of the mothers, $67 \%(n=29)$ reported having had one or more serious overdoses. Eleven of the mothers $(25.6 \%)$ were receiving medically assisted rehabilitation and were prescribed either Methadone or Buprenorphine, and four $(9.3 \%)$ mothers were prescribed medication for Attention Deficit Hyperactivity Disorder (ADHD) Eight $(18.6 \%)$ women reported regularly using other types of prescribed medications, including anxiolytics, sedatives or anti-depressants.

The majority of the mothers reported alcohol to be the first substance they used. When investigating onset-age, nearly all of the mothers $98 \%(n=42)$ reported having used alcohol and cannabis, with an average onset-age of 13.1 years for alcohol and 16.2 years for cannabis. A majority of the mothers, $86 \%$, also reported using prescribed medication illegally, with an average onset-age of 18.1 years. The average onset-age for the use of stimulants was 17.8 years, and $88.4 \%$ of the mothers reported having used the substance at one point in time. Although a majority of the mothers also reported having tried opioids $(58 \%)$, this was a minor group compared to reports of usage of other substances. The onset-age for the use of opioids was also somewhat older, with an average onset-age of 20.3 years. The majority of mothers in our sample, $86.0 \%$, reported multi-substance use.

We found a large variability in PRF scores in the group of mothers. However, scores indicated that overall PRF in the group was poor, as $74.4 \%$ of the mothers scored 3 or lower, with a mean PRF score of 2.91 ( $\mathrm{SD}=1.17$, skewness was -.09). T-scores identified considerable within group variability for distinct cognitive functions. Cognitive flexibility and 
inhibition, and to some extent working memory, stood out as being low in our sample compared to the average scores expected within a normal population. Planning capacities, letter and category fluency were close to the expected average in a normal population, however, with a large within group variability.

The mean total IQ was 94.1, with a rather large difference between verbal IQ: 89.7, and non-verbal IQ: 98.8, qualifying this group of mothers on the low end of average for verbal capacities, but on average for non-verbal capacities.

The mothers in our study qualified for several SUD diagnoses, and 28 (65.1\%) of the mothers had one or more diagnosis for mental health issues in addition to the SUD diagnosis according to ICD-10 (World Health Organization, 1993). Eight (18.6\%) of the mothers qualified for F10 (mental and behavioural disorders due to the use of alcohol), 24 (55.8\%) qualified for F11, (mental and behavioural disorders due to the use of opioids). Whereas 27 $(62.8 \%)$ of the mothers qualified for F12 (mental and behavioural disorders due to use of cannabinoids), $58.1 \%(n=25)$ had a diagnosis of mental and behavioural disorders due to the use of other stimulants, specifically amphetamines. None of the mothers qualified for any of the other SUD diagnoses.

The mothers in our study qualified for numerous mental health diagnoses. During assessment with the M.I.N.I plus version 5.0.0, Norwegian version (Mordal et al., 2010), $37.2 \%(N=16)$ of the women reported an ongoing depression. Two $(4.7 \%)$ were diagnosed with bipolar affect disorder. Twenty-six (60.5\%) mothers had a panic disorder and $12(27.9 \%)$ and $21(48.8 \%)$ had agoraphobia and social phobia respectively. Twenty-three $(53.5 \%)$ of the mothers qualified for a generalized anxiety disorder (GAD). None of the women had a schizophrenia diagnosis, while $16(37.2 \%)$ of the women reported having an eating disorder that were either anorexia, bulimia, overeating or a combination of these. Only four $(9.3 \%)$ of 
Parental Reflective Functioning and Executive Functioning in Mothers with Substance Use Disorder

the mothers reported having an ADHD diagnosis. Sixteen mothers (37.2\%) reported having a post-traumatic stress disorder (PTSD). As a group, the mothers reported an average score of 2.5 on the HSCL-10, thus indicating a high level of current psychological distress, as shown in Table 1.

See Table 2 for a presentation of inter-correlations between general PRF, EF, IQ and mental health status:

\section{Insert Table 2 about here}

There were significant positive correlations between PRF and the following items: working memory $(r=.74)$, planning $(r=.63)$, cognitive flexibility $(r=.58)$, inhibition $(r=$ $.42)$, but significant negative correlation with mental health status $(r=-.56)$. We also found moderate positive correlations between PRF and total IQ $(r=.44)$, verbal IQ $(r=.41)$, and non-verbal IQ $(r=.33)$. Additionally, we found numerous positive significant correlations between specific EF, in which the following items correlated most highly with each other: inhibition and working memory $(r=.72)$, planning and working memory $(r=.65)$ and cognitive flexibility and working memory $(r=.64)$. There were also significant negative correlations between HSCL-10 and several EF components. There were no significant correlations between PRF and verbal fluency.

Table 3 presents the results of the multiple regression analysis.

\section{Insert Table 3 about here}

Total IQ and mental health explained $37 \%$ of the variance in PRF $\left(\mathrm{R}^{2}=.37\right.$, adjusted $\left.\mathrm{R}^{2}=.34, \mathrm{~F}=11.8, \mathrm{df}=2, \mathrm{p}<.000\right)$. Adding the EF-score increased the explained PRF variance to $41 \%\left(\mathrm{R}^{2}=.41\right)$, i.e. an increase of only $4 \%\left(\Delta \mathrm{R}^{2}=.04\right)$, which was not significant $(\mathrm{F}=2.6$, $\mathrm{df}=1, \mathrm{p}=.12$ ). Thus, controlled for IQ and mental health there was no significant association 
between EF and PRF. Mental health showed a significant negative association with PRF, that is, we found that less distress was associated with higher PRF. Therefore, it was interesting to look more closely into differences between mothers who had a negative to low PRF and mothers with an adequate to high PRF. These results are described in more detail in Part 2 of the study.

\title{
Results for Part 2
}

In Table 4 we present differences in reported preference for particular substances and multiple substance use between mothers with negative to low PRF and mothers with adequate to high PRF.

\section{Insert Table 4 about here}

We found no significant differences between the groups based on a preference for any particular substance, except that mothers with a negative to low PRF were found to significantly report more frequent patterns of multiple substance abuse $\left(\chi^{2}=7.3, \mathrm{df}=1, \mathrm{p}=\right.$ $\mathrm{p}<.01$ ), compared to mothers with an adequate to high PRF.

Chi-square tests were conducted to test the differences in the use of prescribed medications, including Buprenorphine, Methadone, and medication for ADHD, anxiolytics, sedatives or anti-depressants between mothers with adequate to high RF and mothers with negative to low RF. Results indicated there were no significant differences between the groups $\left(\chi^{2}=.92, \mathrm{df}=1, \mathrm{p}=.34\right)$.

In Table 5, differences between mothers with a negative to low PRF and mothers with an adequate to high PRF based on substance use onset-age and SUD onset-age are presented:

\author{
Insert Table 5 about here
}


Parental Reflective Functioning and Executive Functioning in Mothers with Substance Use Disorder

The MANOVA analysis showed significant differences between the two groups regarding onset-age concerning all substances. Mothers with a negative to low PRF had a significantly earlier onset age of substance use of the following substances: alcohol $(\mathrm{F}=9.1$, $\mathrm{df}=1, \mathrm{p}<.01)$, prescribed medications $(\mathrm{F}=11.0, \mathrm{df}=1, \mathrm{p}<.01)$, cannabis $(\mathrm{F}=8.7, \mathrm{df}=1, \mathrm{p}<.01)$, stimulants $(\mathrm{F}=6.0, \mathrm{df}=1, \mathrm{p}<.01)$ and opioids $(\mathrm{F}=7.0, \mathrm{df}=1, \mathrm{p}<.01)$.

We also found significant age differences between the two groups when reporting the onset of problems with a particular substance at a level qualifying for a SUD diagnosis. Mothers with a negative to low PRF developed a SUD significantly earlier than mothers with an adequate to high PRF on the following substances: alcohol $(\mathrm{F}=17.7, \mathrm{df}=1, \mathrm{p}<.01)$, prescribed medications $(\mathrm{F}=8.1, \mathrm{df}=1, \mathrm{p}<.01)$, cannabis $(\mathrm{F}=6.9, \mathrm{df}=1, \mathrm{p}<.01)$ and opioids $(\mathrm{F}=13.4, \mathrm{df}=1, \mathrm{p}<.01)$, but not to stimulants.

As seen in Table 6, there were significant differences in a number of EF components when we compared mothers with a negative to low PRF to mothers with an adequate to high PRF controlling for IQ and mental health status (HSCL-10):

\section{Insert Table 6 about here}

Mothers with a negative to low PRF performed significantly poorer than mothers with an adequate to high PRF on the following $\mathrm{EF}$ : working memory $(\mathrm{F}=7.3, \mathrm{df}=1, \mathrm{p}<.01)$, cognitive flexibility $(\mathrm{F}=4.7, \mathrm{df}=1, \mathrm{p}<.05)$ and planning $(\mathrm{F}=5.6, \mathrm{df}=1, \mathrm{p}<.05)$, but not on inhibition, verbal or categorical fluency.

In summary, the findings revealed that there were several significant associations between PRF, EF, IQ and psychological distress. PRF was significantly associated with working memory, planning, cognitive flexibility and inhibition, as well as with IQ. Psychological distress was negatively associated with PRF and EF, specifically working 
memory, planning, cognitive flexibility and inhibition. When we controlled for mental health status and total IQ, the association between EF and PRF was no longer significant in the mothers as a group; however, mental health showed a significant negative association with PRF. We found numerous between-group differences when we separated the group of mothers based on RF level though (negative to low vs. adequate to high), even after controlling for total IQ and mental health status. Mothers with a negative to low PRF reported a significantly earlier onset age of substance use and age of acquiring a SUD diagnosis, as well as more often reporting multiple substance abuse compared to mothers with an adequate to high PRF. Mothers with an adequate to high PRF also exhibited significantly higher scores in working memory, cognitive flexibility and planning capacities, but not in inhibition, verbal and category fluency compared to mothers with a negative to low PRF

\section{Discussion}

\section{Part 1}

Mothers in this study demonstrated a lower capacity for PRF compared to what is expected in a normal population (Fonagy \& Target, 1997; Slade, 2005), and in a vulnerable or stressed population (Pajulo et al., 2012; Rutherford et al., 2015; Taubner et al., 2013). Although there were variations within the group, the mothers exhibited an average PRF score lower than 3 , indicating that as a group, the ability to keep a mental model of oneself and the child in mind was poorly integrated, although not completely absent. In addition, in previous studies of SUD populations, including studies of mothers with SUD, deficits in EF are reported (Cuevas, Deater $\square$ Deckard, Kim $\square$ Spoon, Watson, Morasch et al., 2014; DeaterDeckard, 2014; Koob \& Volkow, 2016; Schmidt, Pennington, Cardoos, Durazzo, \& 
Meyerhoff, 2017). These studies support our findings of impairments in cognitive flexibility, inhibition and working memory. Contrary to our hypothesis, and previous studies in SUD populations (Fernández-Serrano et al., 2010; Verdejo-García \& Pérez-García, 2007), verbal fluency and category fluency were within the normal range in the mothers in this study.

Our results partly support our main hypothesis that PRF relates positively to EF. We found moderate to strong positive correlations between PRF, working memory, planning, cognitive flexibility and inhibition. In contrast to our results, previous studies have found no significant associations between PRF and EF in a normal population of mothers with infants (Turner et al., 2008), or in a sub-clinical group of mothers with older children (Capstick, 2008). It is possible that the association between PRF and EF were more relevant in a clinical group like ours that exhibited considerable vulnerability in both EF and PRF. When we controlled for IQ and mental health problems, the unique contribution of EF on PRF was not significant. However, psychological distress was significantly related to PRF. In accordance with our results, previous studies have reported that psychological distress may exhaust emotion regulation capacities so that it decreases the effectiveness of EF components and PRF (Heim, Shugart, Craighead, \& Nemeroff, 2010; Rutherford, Booth, Crowley, \& Mayes, 2016). Psychological distress could also affect the capacity for flexible thinking and attention by impairing the capacity for perspective taking (Allen \& Fonagy, 2002). Supporting our results, numerous studies have demonstrated that mental health issues adversely affect RF (Borelli, West, Decoste, \& Suchman, 2012; Conklin, Bradley, \& Westen, 2006; Lemma, Target, \& Fonagy, 2011; Luyten, van Houdenhove, Lemma, Target, \& Fonagy, 2012). Our findings indicate that psychological distress significantly influences PRF capacity in mothers with a SUD and we suggest that individual differences needs to be taken into consideration for a better understanding of the association between PRF and EF. 


\section{Part 2.}

In the second part of the study, our aim was to investigate whether differences within the group of mothers with a SUD existed based on PRF. Contrary to our hypothesis, there were no significant differences between the type of substance used and PRF level. We expected that the use of substances commonly associated with severe substance abuse (i.e. opioids and central stimulants) would be more common in the group of mothers with a negative to low PRF. A link between preferred substance and PRF level and a link between preferred substance and successful interventions targeting PRF have previously been reported (Pajulo et al., 2012). In addition, one study found an association between type of preferred substance and social cognition (Quednow, 2017), which is considered a capacity related to RF (Humfress, O'Connor, Slaughter, Target, \& Fonagy, 2002). Although we did not find any significant differences in a preferred substance based on PRF level, multiple substance abuse was significantly more frequent in mothers with a negative to low PRF. It could be that a potentially more chaotic use of substances reflected PRF level more than any particular type of substance preference. Furthermore, it seems that our results are supported by a study that found an association between usage of multiple substances and impaired ToM (SanvicenteVieira et al., 2017). Together, our findings suggest that the group of mothers with a negative to low PRF may have had challenges in regulating complex affective states which could have contributed to the need to use many different substances simultaneously to manage arousal.

We found between group differences in PRF depending on the onset age of substance use. Mothers with a negative to low PRF started using substances significantly earlier compared to mothers with an average to high PRF. The effect was present for all substances reported in the group (e.g. alcohol, cannabis, prescribed medication, stimulants and opioids). 
Moreover, mothers with a negative to low PRF developed SUD significantly earlier when reporting an addiction to alcohol, prescribed medications, cannabis and opioids, but surprisingly not to stimulants. Interestingly, the onset of a SUD was during adolescence for all types of substances for mothers with a negative to low PRF, whereas mothers with an adequate to high PRF developed a SUD in adulthood. Early onset of substance use has previously been associated with a low PRF (Suchman, McMahon, Zhang, Mayes, \& Luthar, 2006). This supports our findings that onset-age may be related to PRF capacity. Furthermore, early onset-age of substance use has been suggested as a precursor of severe substance abuse, mental health problems and psychosocial adversity (DeWit, Adlaf, Offord, \& Ogborne, 2000; Jordan \& Andersen, 2016; Richmond-Rakerd, Slutske, Lynskey, Agrawal, Madden et al., 2016), and according to our results, possibly impaired mentalizing abilities. Multiple studies have proposed early substance use to adversely impact brain development, especially for prefrontal cortex functions (PFC) (Andersen, 2016; Lubman, Yücel, \& Hall, 2007). PFC functions are important for the development of both EF (Davidson, 2001; Tekin \& Cummings, 2002) and mentalizing skills (Frith \& Frith, 2003; Frith \& Frith, 2006; Powell, Lewis, Dunbar, García-Fiñana, \& Roberts, 2010). Taken together, these findings imply that the early onset of substance use heightens the risk of an impaired development of PRF. Another possibility is that vulnerability in PRF and EF could have been present before the onset of substance use, due to either genetic factors (Richmond-Rakerd et al., 2016) or adverse childhood experiences (Anda, Felitti, \& Corwin, 2014; Bick \& Nelson, 2016). Some of the mothers might have been at risk for development of diverse psychological problems, including SUD (Tarter \& Horner, 2015). An early onset-age of SUD may also have affected normal neuropsychological development, possibly leading to deficits in both PRF and EF. A lack of social and emotional experiences normally present in adolescence and young 
adulthood might have caused heightened levels of emotional dysregulation and stress, a factor known to affect both PRF (Rutherford et al., 2015) and EF (Zelazo \& Cunningham, 2007).

As expected, there were significantly more deficits in a number of EF components for mothers with a negative to low PRF, even after controlling for psychological distress and IQ. Interestingly, the mothers with an adequate to high PRF performed in accordance with expected norms in a normal population on all the EF components. It appeared that when an adequate EF was present, PRF and EF were well coordinated and appeared to be consistently interconnected.

Mothers with negative to low PRF exhibited significantly poorer capacities in working memory. Working memory refers to the capacity to remain emotionally regulated when processing new and unknown information, as well as integrating information from multiple sources (Schmeichel, Volokhov, \& Demaree, 2008). Therefore, working memory is an important capacity in caregiving (Gonzalez, 2015) and emotion regulation (Rutherford et al., 2016). Working memory is required for complex cognitive tasks such as reasoning and problem solving (Miyake, Friedman, Emerson, Witzki, Howerter et al., 2000; Miyake \& Shah, 1999), and considered an essential capacity for reflective learning in childhood (Zelazo, 2015). We suggest the same process to be essential for the development of adequate PRF.

Mothers with negative to low PRF also showed significantly more deficits in planning capacities compared to mothers with adequate to high PRF. Our results support previous research that have found SUD populations have impairments in planning (Carlson, Moses, \& Claxton, 2004). Specifically, planning in low structured situations that are highly representative of everyday activities are considered particularly challenging in individuals with a SUD (Janke van Holst \& Schilt, 2011; Valls-Serrano et al., 2016). Deficits in planning impair the capacity to prepare and organise for future events and outcomes, as well as the 
ability to focus. Although we could not find any studies investigating the explicit relationship between planning and RF, research on ToM suggests that planning is an essential skill for making effective reflections about oneself and others (Carlson et al., 2015; Carlson et al., 2004). Based on our results, we suggest that planning is an important component for adequate PRF.

Perspective taking is an essential capacity for adequate EF (Bradford, Jentzsch, \& Gomez, 2015; Decety \& Jackson, 2004). Our results indicate that mothers with adequate to high PRF had significantly higher cognitive flexibility capacities compared to mothers with negative to low PRF. These results support studies that have found deficits in perspective taking to be negatively related to cognitive flexibility (Carlson et al., 2015; Stuss \& Knight, 2002; Wunderli, Vonmoos, Niedecker, Hulka, Preller et al., 2016). Individuals easily distracted by stimuli have been found to exhibit deficits in attributing complex emotional and motivational states to others (Decety \& Sommerville, 2003). According to our results, the capacity to maintain attentional control and ability to shift focus are functions necessary for adequate PRF. Indeed, the capacity to mentalize requires the individual to be regulated emotionally and attentively, in a manner that allows for perspective taking (Allen, Fonagy, \& Bateman, 2008) and impairments in these regulatory capacities have been associated with deficits in EF (Hofmann, Schmeichel, \& Baddeley, 2012; Zelazo \& Cunningham, 2007). Difficulties in controlling and regulating emotions have also been proposed to be a core component of SUD (Schore, 2005), and in a low RF (Fonagy et al., 2004). Studies have shown that parents with a SUD struggle to conceptualise and experience their own emotions while simultaneously reflecting about the mental states of the child (Neger \& Prinz, 2015; Slade, Grienenberger, Bernbach, Levy, \& Locker, 2005). We suggest that psychological distress, non-reflective habitual responses or emotional dysregulation might overrule EF, 
thereby having a negative effect on the PRF seen in the group of mothers with negative to low PRF in this study. Therefore, it could be that SUD mothers with adequate to high PRF may have a more sophisticated EF system.

\section{Limitations}

Although robust findings, the results should be considered preliminary due to sample size. Replication studies should include a control group and a larger number of respondents to help strengthen the power of analysis. Furthermore, as an exploratory analysis/study we predominately conducted correlations and regression analysis to analyse the data and therefore determining causality between variables is limited. It remains unclear whether the effects seen are a product of a SUD, or whether pre-existing or comorbid factors explain the variation and associations between PRF and EF. Although we attempted to control for mental health by including HSCL-10 in our analyses, our results could have been due to underlying mental health issues commonly reported to be comorbid with SUD (Choi \& Ryan, 2007; Miles, Svikis, Kulstad, \& Haug, 2001). Mothers with SUD have a significant heightened occurrence of early childhood and lifetime trauma, including neglect and abuse (Ashley, Marsden, \& Brady, 2003; Wilsnack, Vogeltanz, Klassen, \& Harris, 1997), and these factors/ experiences are known to affect EF (Teicher \& Samson, 2016), RF (Nazarov, Frewen, Parlar, Oremus, MacQueen et al., 2014) as well as SUD (Cecil, Viding, Fearon, Glaser, \& McCrory, 2017). Even though we reported a high prevalence of PTSD, the dynamics underlying the possible developmental trauma is not thoroughly investigated in the current study. These issues raised should be considered for future research.

\section{Clinical implications}


Parental Reflective Functioning and Executive Functioning in Mothers with Substance Use Disorder

Resiliency studies strongly suggest the importance of individually adjusted interventions to help address maternal functioning in clinical populations (Luthar, 2015; Rutherford et al., 2015). Based on our results, we suggest EF and PRF to be related phenomena in mothers with negative to low PRF and EF and in mothers with adequate capacities. The relationship between the two phenomena needs to be taken into consideration when trying to understand the possible challenges a certain group of mothers with a SUD may experience in parenting. The enhancement of PRF in mothers with a SUD has been found to be effective for improving parenting capabilities and preventing child neglect and abuse (Pajulo et al., 2012; Suchman, DeCoste, Ordway, \& Mayes, 2012). Even so, a group of mothers with a low PRF and deficits in EF might not benefit on commonly used intervention strategies. We suggest that the group of mothers with deficits in PRF and EF would benefit from interventions customized to improve selective executive capacities as a prerequisite to enhance poor PRF. Mothers with a SUD are a stigmatized group often considered homogenous and difficult to offer appropriate interventions. This study contributes to an understanding of the importance of individually customized interventions and how these could be carried out more effectively. It is of further interest to consider how capacities, deficits and the relationship between PRF and EF seen in this study may affect the relationship between mother and child, and how adjustments in interventions can help strengthen these capacities. 


\section{REFERENCES}

Abu-Akel, A., \& Shamay-Tsoory, S. (2011). Neuroanatomical and neurochemical bases of theory of mind. Neuropsychologia, 49(11), 2971-2984.

Allen, J. G., \& Fonagy, P. (2002). The development of mentalizing and its role in psychopathology and psychotherapy. Meninger Clinic, Topeka, KS.

Allen, J. G., Fonagy, P., \& Bateman, A. W. (2008). Mentalizing in clinical practice: American Psychiatric Pub.

Anda, R., Felitti, V. J., \& Corwin, D. (2014). Adverse Childhood Experiences and Long-Term Health. ACEs: Informing Best Practice, AVA/NHCVA, Section, 1.

Andersen, C. J. J. S. L. (2016). Sensitive periods of substance abuse: Early risk for the transition to dependence. Neuropsychopharmacology, 31, 1946-1956.

Apperly, I. A., Samson, D., \& Humphreys, G. W. (2009). Studies of adults can inform accounts of theory of mind development. Developmental Psychology, 45(1), 190.

Ashley, O. S., Marsden, M. E., \& Brady, T. M. (2003). Effectiveness of substance abuse treatment programming for women: A review. The American Journal of Drug and Alcohol Abuse, 29(1), 19-53.

Association, A. P. (2000). Diagnostic and statistical manual of mental disorders DSM-IV-TR fourth edition (text revision).

Atkinson, L., Leung, E., Goldberg, S., Benoit, D., Poulton, L., Myhal, N., .. Kerr, S. (2009). Attachment and selective attention: Disorganization and emotional Stroop reaction time. Development and Psychopathology, 21(1), 99-126.

Austin, G., Groppe, K., \& Elsner, B. (2014). The reciprocal relationship between executive function and theory of mind in middle childhood: A 1-year longitudinal perspective. Frontiers in Psychology, 5.

Baron-Cohen, S. (1995). Mindblindness: An essay on autism and theory of mind. Cambridge, MA: Bradford: MIT press.

Barrett, J., \& Fleming, A. S. (2011). Annual research review: All mothers are not created equal: Neural and psychobiological perspectives on mothering and the importance of individual differences. Journal of Child Psychology and Psychiatry, 52(4), 368-397.

Bechara, A. (2005). Decision making, impulse control and loss of willpower to resist drugs: A neurocognitive perspective. Nature Neuroscience, 8(11), 1458-1463. doi:10.1038/nn1584

Bechara, A., Dolan, S., Denburg, N., Hindes, A., Anderson, S. W., \& Nathan, P. E. (2001). Decisionmaking deficits, linked to a dysfunctional ventromedial prefrontal cortex, revealed in alcohol 
and stimulant abusers. Neuropsychologia, 39(4), 376-389. doi:10.1016/S00283932(00)00136-6

Bick, J., \& Nelson, C. A. (2016). Early adverse experiences and the developing brain. Neuropsychopharmacology, 41(1), 177-196.

Borelli, J. L., West, J. L., Decoste, C., \& Suchman, N. E. (2012). Emotionally avoidant language in the parenting interviews of substance-dependent mothers: Associations with reflective functioning, recent substance use, and parenting behavior. Infant Mental Health Journal, 33(5), 506-519. doi:10.1002/imhj.21340

Bouchard, M.-A., Target, M., Lecours, S., Fonagy, P., Tremblay, L.-M., Schachter, A., \& Stein, H. (2008). Mentalization in adult attachment narratives: Reflective functioning, mental states, and affect elaboration compared. Psychoanalytic Psychology, 25(1), 47.

Bradford, E. E., Jentzsch, I., \& Gomez, J.-C. (2015). From self to social cognition: Theory of mind mechanisms and their relation to executive functioning. Cognition, 138, 21-34.

Bull, R., Phillips, L. H., \& Conway, C. A. (2008). The role of control functions in mentalizing: Dual-task studies of theory of mind and executive function. Cognition, 107(2), 663-672.

Capstick, C. C. (2008). The role of higher-order cognition in parental reflective functioning: $A$ correlational study of executive and reflective capacities and the related contributions of substance abuse and depression: ProQuest.

Carlson, S. M., Claxton, L. J., \& Moses, L. J. (2015). The relation between executive function and theory of mind is more than skin deep. Journal of Cognition and Development, 16(1), 186197.

Carlson, S. M., Moses, L. J., \& Claxton, L. J. (2004). Individual differences in executive functioning and theory of mind: An investigation of inhibitory control and planning ability. Journal of Experimental Child Psychology, 87(4), 299-319.

Cash, S. J., \& Wilke, D. J. (2003). An ecological model of maternal substance abuse and child neglect: Issues, analyses, and recommendations. American Journal of Orthopsychiatry, 73(4), 392.

Cecil, C. A., Viding, E., Fearon, P., Glaser, D., \& McCrory, E. J. (2017). Disentangling the mental health impact of childhood abuse and neglect. Child Abuse \& Neglect, 63, 106-119.

Chico, E., Gonzalez, A., Ali, N., Steiner, M., \& Fleming, A. S. (2014). Executive function and mothering: Challenges faced by teenage mothers. Developmental Psychobiology, 56(5), 1027-1035.

Choi, S., \& Ryan, J. P. (2007). Co-occurring problems for substance abusing mothers in child welfare: Matching services to improve family reunification. Children and Youth Services Review, 29(11), 1395-1410.

Conklin, C. Z., Bradley, R., \& Westen, D. (2006). Affect regulation in borderline personality disorder. The Journal of Nervous and Mental Disease, 194(2), 69-77.

Cuevas, K., Deater-Deckard, K., Kim-Spoon, J., Watson, A. J., Morasch, K. C., \& Bell, M. A. (2014). What's mom got to do with it? Contributions of maternal executive function and caregiving to the development of executive function across early childhood. Developmental Science, $17(2), 224-238$.

Davidson, R. J. (2001). The neural circuitry of emotion and affective style: Prefrontal cortex and amygdala contributions. Social Science Information, 40(1), 11-37. doi:10.1177/053901801040001002

Deater-Deckard, K. (2014). Family matters intergenerational and interpersonal processes of executive function and attentive behavior. Current Directions in Psychological Science, 23(3), 230-236.

Deater-Deckard, K., Sewell, M. D., Petrill, S. A., \& Thompson, L. A. (2010). Maternal working memory and reactive negativity in parenting. Psychological Science, 21(1), 75. doi:10.1177/0956797609354073

Decety, J., \& Jackson, P. L. (2004). The functional architecture of human empathy. Behavioral and Cognitive Neuroscience Reviews, 3(2), 71-100. 
Parental Reflective Functioning and Executive Functioning in Mothers with Substance Use Disorder

Decety, J., \& Sommerville, J. A. (2003). Shared representations between self and other: A social cognitive neuroscience view. Trends in Cognitive Sciences, 7(12), 527-533.

Delis, D. C., Kaplan, E., \& Kramer, J. H. (2001). Delis-Kaplan executive function system (D-KEFS): Psychological Corporation.

Derogatis, L. R., Lipman, R. S., Rickels, K., Uhlenhuth, E. H., \& Covi, L. (1974). The Hopkins Symptom Checklist (HSCL): A self-report symptom inventory. Behavioral Science, 19(1), 1-15.

DeWit, D. J., Adlaf, E. M., Offord, D. R., \& Ogborne, A. C. (2000). Age at first alcohol use: A risk factor for the development of alcohol disorders. American Journal of Psychiatry, 157(5), 745-750.

Dolan, S. L., Bechara, A., \& Nathan, P. E. (2008). Executive dysfunction as a risk marker for substance abuse: The role of impulsive personality traits. Behavioral Sciences \& the Law, 26(6), 799-822.

Dvir, Y., Ford, J. D., Hill, M., \& Frazier, J. A. (2014). Childhood maltreatment, emotional dysregulation, and psychiatric comorbidities. Harvard Review of Psychiatry, 22(3), 149.

Fernández-Serrano, M. J., Pérez-García, M., Perales, J. C., \& Verdejo-García, A. (2010). Prevalence of executive dysfunction in cocaine, heroin and alcohol users enrolled in therapeutic communities. European Journal of Pharmacology, 626(1), 104-112.

Fischer-Kern, M., Fonagy, P., Kapusta, N. D., Luyten, P., Boss, S., Naderer, A., . . Leithner, K. (2013). Mentalizing in female inpatients with major depressive disorder. The Journal of Nervous and Mental Disease, 201(3), 202-207.

Fisher, N., \& Happé, F. (2005). A training study of theory of mind and executive function in children with autistic spectrum disorders. Journal of Autism and Developmental Disorders, 35(6), 757771.

Fonagy, P., Gergely, \& Jurist, . (2004). Affect regulation, mentalization and the development of the self: Karnac Books.

Fonagy, P.,Steele, M., Steele, H., Leigh, T., Kennedy, R., Mattoon, G., \& Target, M. (1995). Attachment, the reflective self, and borderline states: The predictive specificity of the Adult Attachment Interview and pathological emotional development.

Fonagy, P., Target, M., Steele, H., \& Steele, M. (1998). Reflective-functioning manual, version 5.0, for application to adult attachment interviews. London: University College London.

Fonagy, P., \& Target, M. (1997). Attachment and reflective function: Their role in self-organization. Development and psychopathology, 9(04), 679-700.

Fonagy, P., Target, M., Gergely, G., Allen, J. G., \& Bateman, A. W. (2003). The developmental roots of borderline personality disorder in early attachment relationships: A theory and some evidence. Psychoanalytic Inquiry, 23(3), 412-459.

Friedman, N. P., \& Miyake, A. (2017). Unity and diversity of executive functions: Individual differences as a window on cognitive structure. Cortex, 86, 186-204.

Friedman, N. P., Miyake, A., Corley, R. P., Young, S. E., DeFries, J. C., \& Hewitt, J. K. (2006). Not all executive functions are related to intelligence. Psychological Science, 17(2), 172-179.

Frith, C. D., \& Frith, U. (2003). Development and neurophysiology of mentalizing. Philosophical Transactions of the Royal Society of London B: Biological Sciences, 358(1431), 459-473.

Frith, C. D., \& Frith, U. (2006). The neural basis of mentalizing. Neuron, 50(4), 531-534.

Galinsky, E. (2010). Mind in the making. National Association for the Education of Young Children: Washington, DC.

Giancola, P. R., \& Tarter, R. E. (1999). Executive cognitive functioning and risk for substance abuse. Psychological Science, 10(3), 203-205.

Gonzalez, A. (2015). The role of maternal executive function. Canadian Psychology/Psychologie Canadienne, 56(1), 46.

Gonzalez, A., Atkinson, L., \& Fleming, A. S. (2009). Attachment and the comparative psychobiology of mothering. Handbook of Developmental Social Neuroscience, 225-245. 
Gonzalez, A., Jenkins, J. M., Steiner, M., \& Fleming, A. S. (2012). Maternal early life experiences and parenting: The mediating role of cortisol and executive function. Journal of the American Academy of Child \& Adolescent Psychiatry, 51(7), 673-682.

Górska, D., \& Marszał, M. (2014). Mentalization and theory of mind in borderline personality organization: Exploring the differences between affective and cognitive aspects of social cognition in emotional pathology. Psychiatria Polska, 48, 503-513.

Graham, K. (2004). Disinhibition, impulse control, arousal and gender: Understanding the mechanisms of alcohol's effects on aggression. Addiction, 99(10), 1250-1251. doi:10.1111/j.1360-0443.2004.00891.x

Grant, B. F., \& Dawson, D. A. (1998). Age of onset of drug use and its association with DSM-IV drug abuse and dependence: Results from the National Longitudinal Alcohol Epidemiologic Survey. Journal of Substance Abuse, 10(2), 163-173.

Grienenberger, J., \& Slade, A. (2002). Maternal reflective functioning, mother-infant affective communication, and infant attachment: Implications for psychodynamic treatment with children and families. Psychologist-Psychoanalyst, 22(3).

Gruber, S. A., Sagar, K. A., Dahlgren, M. K., Racine, M., \& Lukas, S. E. (2012). Age of onset of marijuana use and executive function. Psychology of Addictive Behaviors, 26(3), 496.

Haavet, O. R., Sirpal, M. K., Haugen, W., \& Christensen, K. S. (2010). Diagnosis of depressed young people in primary health care-a validation of HSCL-10. Family Practice, cmq078.

Heim, C., Shugart, M., Craighead, W. E., \& Nemeroff, C. B. (2010). Neurobiological and psychiatric consequences of child abuse and neglect. Developmental Psychobiology, 52(7), 671-690.

Hofmann, W., Schmeichel, B. J., \& Baddeley, A. D. (2012). Executive functions and self-regulation. Trends in Cognitive Sciences, 16(3), 174-180.

Hughes, E. K., \& Gullone, E. (2010). Parent emotion socialisation practices and their associations with personality and emotion regulation. Personality and Individual Differences, 49(7), 694-699.

Humfress, H., O'Connor, T. G., Slaughter, J., Target, M., \& Fonagy, P. (2002). General and relationshipspecific models of social cognition: Explaining the overlap and discrepancies. Journal of Child Psychology and Psychiatry, 43(7), 873-883.

Janke van Holst, R., \& Schilt, T. (2011). Drug-related decrease in neuropsychological functions of abstinent drug users. Current Drug Abuse Reviews, 4(1), 42-56.

Jordan, C. J., \& Andersen, S. L. (2016). Sensitive periods of substance abuse: Early risk for the transition to dependence. Developmental Cognitive Neuroscience.

Kalbe, E., Grabenhorst, F., Brand, M., Kessler, J., Hilker, R., \& Markowitsch, H. J. (2007). Elevated emotional reactivity in affective but not cognitive components of theory of mind: $A$ psychophysiological study. Journal of Neuropsychology, 1(1), 27-38.

Kalivas, P. W., \& Volkow, N. D. (2005). The neural basis of addiction: A pathology of motivation and choice. American Journal of Psychiatry, 162(8), 1403-1413.

Kelly, K., Slade, A., \& Grienenberger, J. F. (2005). Maternal reflective functioning, mother-infant affective communication, and infant attachment: Exploring the link between mental states and observed caregiving behavior in the intergenerational transmission of attachment. Attachment \& Human Development, 7(3), 299-311.

Kessler, F., Cacciola, J., Alterman, A., Faller, S., Souza-Formigoni, M. L., Cruz, M. S., ... Pechansky, F. (2012). Psychometric properties of the sixth version of the Addiction Severity Index (ASI-6) in Brazil. Revista Brasileira de Psiquiatria, 34(1), 24-33.

Kienhuis, M., Rogers, S., Giallo, R., Matthews, J., \& Treyvaud, K. (2010). A proposed model for the impact of parental fatigue on parenting adaptability and child development. Journal of Reproductive and Infant Psychology, 28(4), 392-402.

Kokkevi, A., \& Hartgers, C. (1995). EuropASI: European adaptation of a multidimensional assessment instrument for drug and alcohol dependence. European Addiction Research, 1(4), 208-210. 
Parental Reflective Functioning and Executive Functioning in Mothers with Substance Use Disorder

Koob, G. F., \& Volkow, N. D. (2016). Neurobiology of addiction: A neurocircuitry analysis. The Lancet Psychiatry, 3(8), 760-773.

Kovács, Á. M., Téglás, E., \& Endress, A. D. (2010). The social sense: Susceptibility to others' beliefs in human infants and adults. Science, 330(6012), 1830-1834.

Lauritzen, G. O. (2010). European Addiction Severity Index (EuropASI) i en oppfølgingsstudie av narkotikabrukere i behandling. Refleksjon om kvaliteter ved instrumentet for forskning og praksisformål.

Lemma, A., Target, M., \& Fonagy, P. (2011). The development of a brief psychodynamic intervention (dynamic interpersonal therapy) and its application to depression: A pilot study. Psychiatry: Interpersonal \& Biological Processes, 74(1), 41-48.

Levy, D. W., \& Truman, S. (2002). Reflective functioning as mediator between drug use, parenting stress and child behavior. Paper presented at the College on Problems of Drug Dependence Annual Meeting, Quebec.

Levy, D. W., Truman, S., \& Mayes, L. (2001). The impact of prenatal cocaine use on maternal reflective functioning. Paper presented at the Proceedings of the Meeting of the Society for Research in Child Development.

Leyro, T. M., Zvolensky, M. J., \& Bernstein, A. (2010). Distress tolerance and psychopathological symptoms and disorders: A review of the empirical literature among adults. Psychological Bulletin, 136(4), 576.

Lubman, D. I., Yücel, M., \& Hall, W. D. (2007). Substance use and the adolescent brain: A toxic combination? Journal of Psychopharmacology, 21(8), 792-794.

Luthar, S. S. (2015). Mothering mothers. Research in Human Development, 12(3-4), 295-303.

Luthar, S. S., \& Suchman, N. E. (2000). Relational Psychotherapy Mothers' Group: A developmentally informed intervention for at-risk mothers. Development and Psychopathology, 12(02), 235253.

Luyten, P., van Houdenhove, B., Lemma, A., Target, M., \& Fonagy, P. (2012). A mentalization-based approach to the understanding and treatment of functional somatic disorders. Psychoanalytic Psychotherapy, 26(2), 121-140.

Lyons-Ruth, K., Bronfman, E., \& Atwood, G. (1999). A relational diathesis model of hostile-helpless states of mind: Expressions in mother-infant interaction. In J. Solomon, George, Carol. (Ed.), Attachment Disorganization (pp. 33-70). New York, NY, US: Guilford.

Mayes, L., \& Truman, S. (2002). Substance abuse and parenting. Handbook of Parenting, 4, 329-359.

McLellan, A. T., Kushner, H., Metzger, D., Peters, R., Smith, I., Grissom, G., . . Argeriou, M. (1992). The fifth edition of the Addiction Severity Index. Journal of Substance Abuse Treatment, 9(3), 199-213.

Miles, D. R., Svikis, D. S., Kulstad, J. L., \& Haug, N. A. (2001). Psychopathology in pregnant drugdependent women with and without comorbid alcohol dependence. Alcoholism: Clinical and Experimental Research, 25(7), 1012-1017.

Miller, E., \& Cohen, J. (2001). An integrative theory of prefrontal cortex function. Annual Review of Neuroscience, 24, 167-202.

Mintzer, M. Z., \& Stitzer, M. L. (2002). Cognitive impairment in methadone maintenance patients. Drug and Alcohol Dependence, 67(1), 41-51. doi:10.1016/S0376-8716(02)00013-3

Miyake, A., Friedman, N. P., Emerson, M. J., Witzki, A. H., Howerter, A., \& Wager, T. D. (2000). The unity and diversity of executive functions and their contributions to complex "frontal lobe" tasks: A latent variable analysis. Cognitive Psychology, 41(1), 49-100.

Miyake, A., \& Shah, P. (1999). Models of working memory: Mechanisms of active maintenance and executive control: Cambridge University Press.v

Mordal, J., Gundersen, $\varnothing$., \& Bramness, J. (2010). Norwegian version of the Mini-International Neuropsychiatric Interview: Feasibility, acceptability and test-retest reliability in an acute psychiatric ward. European Psychiatry, 25(3), 172-177. 
Parental Reflective Functioning and Executive Functioning in Mothers with Substance Use Disorder

Moreno-López, L., Stamatakis, E. A., Fernández-Serrano, M. J., Gómez-Río, M., Rodríguez-Fernández, A., Pérez-García, M., \& Verdejo-García, A. (2012). Neural correlates of hot and cold executive functions in polysubstance addiction: Association between neuropsychological performance and resting brain metabolism as measured by positron emission tomography. Psychiatry Research: Neuroimaging, 203(2), 214-221.

Nazarov, A., Frewen, P., Parlar, M., Oremus, C., MacQueen, G., McKinnon, M., \& Lanius, R. (2014). Theory of mind performance in women with posttraumatic stress disorder related to childhood abuse. Acta Psychiatrica Scandinavica, 129(3), 193-201.

Neger, E. N., \& Prinz, R. J. (2015). Interventions to address parenting and parental substance abuse: Conceptual and methodological considerations. Clinical Psychology Review, 39, 71-82.

Oldrati, V., Patricelli, J., Colombo, B., \& Antonietti, A. (2016). The role of dorsolateral prefrontal cortex in inhibition mechanism: A study on cognitive reflection test and similar tasks through neuromodulation. Neuropsychologia, 91, 499-508.

Pajulo, M., Pyykkönen, N., Kalland, M., Sinkkonen, J., Helenius, H., Punamäki, R. I., \& Suchman, N. (2012). Substance-abusing mothers in residential treatment with their babies: Importance of pre- and postnatal maternal reflective functioning. Infant Mental Health Journal, 33(1), 70 81. doi:10.1002/imhj.20342

Pajulo, M., Suchman, N., Kalland, M., \& Mayes, L. (2006). Enhancing the effectiveness of residential treatment for substance abusing pregnant and parenting women: Focus on maternal reflective functioning and mother-child relationship. Infant Mental Health Journal, 27(5), 448-465.

Pennington, B. F., \& Ozonoff, S. (1996). Executive functions and developmental psychopathology. Journal of Child Psychology and Psychiatry, 37(1), 51-87.

Powell, J. L., Lewis, P. A., Dunbar, R. I., García-Fiñana, M., \& Roberts, N. (2010). Orbital prefrontal cortex volume correlates with social cognitive competence. Neuropsychologia, 48(12), 35543562.

Premack, D., \& Woodruff, G. (1978). Does the chimpanzee have a theory of mind? Behavioral and Brain Sciences, 1(04), 515-526.

Quednow, B. B. (2017). Social cognition and interaction in stimulant use disorders. Current Opinion in Behavioral Sciences, 13, 55-62.

Richmond-Rakerd, L. S., Slutske, W. S., Lynskey, M. T., Agrawal, A., Madden, P. A., Bucholz, K. K., . . . Martin, N. G. (2016). Age at first use and later substance use disorder: Shared genetic and environmental pathways for nicotine, alcohol, and cannabis. Journal of Abnormal Psychology, $125(7), 946$.

Rigby, J., Conroy, S., Miele-Norton, M., Pawlby, S., \& Happé, F. (2016). Theory of mind as a predictor of maternal sensitivity in women with severe mental illness. Psychological Medicine, 46(9), 1853-1863.

Rudden, M., Milrod, B., Target, M., Ackerman, S., \& Graf, E. (2006). Reflective functioning in panic disorder patients: A pilot study. Journal of the American Psychoanalytic Association, 54(4), 1339-1343.

Rush, J., First, M. B., \& Blacker, D. (Eds.) (2008). Handbook of psychiatric measures (2nd ed.). Washington, DC: American Psychiatric Association.

Rutherford, H., Booth, C. R., Crowley, M. J., \& Mayes, L. C. (2016). Investigating the relationship between working memory and emotion regulation in mothers. Journal of Cognitive Psychology, 28(1), 52-59.

Rutherford, H., Booth, C. R., Luyten, P., Bridgett, D. J., \& Mayes, L. C. (2015). Investigating the association between parental reflective functioning and distress tolerance in motherhood. Infant Behavior and Development, 40, 54-63. doi:10.1016/j.infbeh.2015.04.005 
Parental Reflective Functioning and Executive Functioning in Mothers with Substance Use Disorder

Sanvicente-Vieira, B., Romani-Sponchiado, A., Kluwe-Schiavon, B., Brietzke, E., Araujo, R. B., \& GrassiOliveira, R. (2017). Theory of Mind in Substance Users: A Systematic Minireview. Substance Use \& Misuse, 52(1), 127-133.

Schmeichel, B. J., Volokhov, R. N., \& Demaree, H. A. (2008). Working memory capacity and the selfregulation of emotional expression and experience. Journal of Personality and Social Psychology, 95(6), 1526.

Schmidt, T. P., Pennington, D. L., Cardoos, S. L., Durazzo, T. C., \& Meyerhoff, molenbeD. J. (2017). Neurocognition and inhibitory control in polysubstance use disorders: Comparison with alcohol use disorders and changes with abstinence. Journal of Clinical and Experimental Neuropsychology, 39(1), 22-34.

Schore, A. N. (2005). Attachment, affect regulation, and the developing right brain: Linking developmental neuroscience to pediatrics. Pediatrics in Review, 26(6), 204-217.

Shai, D., \& Belsky, J. (2017). Parental embodied mentalizing: How the nonverbal dance between parents and infants predicts children's socio-emotional functioning. Attachment \& Human Development, 19(2), 191-219.

Shonkoff, J. P., Garner, A. S., Siegel, B. S., Dobbins, M. I., Earls, M. F., McGuinn, L., . . Wood, D. L. (2012). The lifelong effects of early childhood adversity and toxic stress. Pediatrics, 129(1), e232-e246.

Siqveland, T., Smith, L., \& Moe, V. (2012). The impact of optimality on maternal sensitivity in mothers with substance abuse and psychiatric problems and their infants at 3 months. Infant Behavior and Development, 35(1), 60-70.

Skowron, E. A., \& Friedlander, M. L. (1998). The Differentiation of Self Inventory: Development and initial validation. Journal of Counseling Psychology, 45(3), 235.

Skutle, A., Bu, E. T. H., Jellestad, F. K., van Emmerik-van Oortmerssen, K., Dom, G., Verspreet, S., ... Konstenius, M. (2015). Early developmental, temperamental and educational problems in 'substance use disorder'patients with and without ADHD. Does ADHD make a difference? Addictive Behaviors Reports, 2, 13-18.

Slade, A. (2005). Parental reflective functioning: An introduction. Attachment \& Human Development, 7(3), 269-281.

Slade, A., Aber, L., Berger, B., Bresgi, I., Kaplan, M., Mayes, L., . . Blatt, S. (2003). Parent Development Interview revised PDI-R2. Unpublished manuscript.

Slade, A., Belsky, J., Aber, J. L., \& Phelps, J. L. (1999). Mothers' representations of their relationships with their toddlers: Llinks to adult attachment and observed mothering. Developmental Psychology, 35(3), 611.

Slade, A., Bernbach, E., Grienenberger, J., Levy, D., \& Locker, A. (2005). Addendum to reflective functioning scoring manual. Unpublished manuscript: The Psychological Center, The City College of New York, New York.

Slade, A., Grienenberger, J., Bernbach, E., Levy, D., \& Locker, A. (2005). Maternal reflective functioning, attachment, and the transmission gap: A preliminary study. Attachment \& Human Devlopment, 7(3), 283-298.

Steele, H., \& Steele, M. (2008). On the origins of reflective functioning. In F. Busch (Ed). Mentalization: Theoretical considerations, research findings, and clinical implications. Psychoanalytic Inquiry Book Series, 29, pp 133-158. NY: Analytic Books.

Strand, B. H., Dalgard, O. S., Tambs, K., \& Rognerud, M. (2003). Measuring the mental health status of the Norwegian population: A comparison of the instruments SCL-25, SCL-10, SCL-5 and MHI-5 (SF-36). Nordic Journal of Psychiatry, 57(2), 113-118.

Stuss, D. T., \& Knight, R. T. (2002). Principles of Frontal Lobe Function. Cary: Cary, NC, USA: Oxford University Press, USA. 
Suchman, N., DeCoste, C., Castiglioni, N., Legow, N., \& Mayes, L. (2008). The Mothers and Toddlers Program: Preliminary findings from an attachment-based parenting intervention for substance-abusing mothers. Psychoanalytic Psychology, 25(3), 499.

Suchman, N., Decoste, C., Leigh, D., \& Borelli, J. (2010). Reflective functioning in mothers with drug use disorders: Implications for dyadic interactions with infants and toddlers. Attachment \& Human Development, 12(6), 567-585. doi:10.1080/14616734.2010.501988

Suchman, N., DeCoste, C., Ordway, M., \& Mayes, L. (2012). Mothering from the inside out: A mentalization-based individual therapy for mothers with substance use disorders. Parenting and substance addiction: Developmental approaches to intervention: Oxford University Press, New York, NY.

Suchman, N., McMahon, T. J., Slade, A., \& Luthar, S. S. (2005). How Early Bonding, Depression, Illicit Drug Use, and Perceived Support Work Together to Influence Drug-Dependent Mothers' Caregiving. American Journal of Orthopsychiatry, 75(3), 431-445.

Suchman, N., McMahon, T. J., Zhang, H., Mayes, L. C., \& Luthar, S. (2006). Substance-abusing mothers and disruptions in child custody: An attachment perspective. Journal of Substance Abuse Treatment, 30(3), 197-204.

Suchman, N., Ordway, M. R., de las Heras, L., \& McMahon, T. J. (2016). Mothering from the Inside Out: Results of a pilot study testing a mentalization-based therapy for mothers enrolled in mental health services. Attachment \& Human development, 18(6), 596-617.

Suchman, N., Pajulo, M., DeCoste, C., \& Mayes, L. (2006). Parenting Interventions for drug-dependent mothers and their young children: The case for an attachment-based approach. Family Relations, 55(2), 211-226.

Tarter, R. E., \& Horner, M. S. (2015). Developmental Pathways to Substance Use Disorder and Cooccurring Psychiatric Disorders in Adolescents. Youth Substance Abuse and Co-occurring Disorders, 1.

Taubner, S., Horz, S., Fischer-Kern, M., Doering, S., Buchheim, A., \& Zimmermann, J. (2013). Internal Structure of the Reflective Functioning Scale. Psychological Assessment, 25(1), 127-135. doi:10.1037/a0029138

Taubner, S., Kessler, H., Buchheim, A., Kächele, H., \& Staun, L. (2011). The role of mentalization in the psychoanalytic treatment of chronic depression. Psychiatry: Interpersonal \& Biological Processes, 74(1), 49-57.

Teicher, M. H., \& Samson, J. A. (2016). Annual Research Review: Enduring neurobiological effects of childhood abuse and neglect. Journal of Child Psychology and Psychiatry.

Tekin, S., \& Cummings, J. L. (2002). Frontal-subcortical neuronal circuits and clinical neuropsychiatry: An update. Journal of Psychosomatic Research, 53(2), 647-654. doi:10.1016/S00223999(02)00428-2

Turner, J. M., Wittkowski, A., \& Hare, D. J. (2008). The relationship of maternal mentalization and executive functioning to maternal recognition of infant cues and bonding. British Journal of Psychology, 99(4), 499-512.

Valiente, C., Lemery-Chalfant, K., \& Reiser, M. (2007). Pathways to problem behaviors: Chaotic homes, parent and child effortful control, and parenting. Social Development, 16(2), 249-267.

Valls-Serrano, C., Verdejo-García, A., \& Caracuel, A. (2016). Planning deficits in polysubstance dependent users: Differential associations with severity of drug use and intelligence. Drug and Alcohol Dependence, 162, 72-78.

Verdejo-García, A., Bechara, A., Recknor, E. C., \& Perez-Garcia, M. (2006). Executive dysfunction in substance dependent individuals during drug use and abstinence: An examination of the behavioral, cognitive and emotional correlates of addiction. Journal of the International Neuropsychological Society, 12(03), 405-415.

Verdejo-Garcıa, A., López-Torrecillas, F., de Arcos, F. A., \& Pérez-Garcıa, M. (2005). Differential effects of MDMA, cocaine, and cannabis use severity on distinctive components of the executive 
functions in polysubstance users: A multiple regression analysis. Addictive Behaviors, 30(1), 89-101.

Verdejo-García, A., \& Pérez-García, M. (2007). Profile of executive deficits in cocaine and heroin polysubstance users: Common and differential effects on separate executive components. Psychopharmacology, 190(4), 517-530.

Vetter, N. C., Altgassen, M., Phillips, L., Mahy, C. E., \& Kliegel, M. (2013). Development of affective theory of mind across adolescence: Disentangling the role of executive functions. Developmental Neuropsychology, 38(2), 114-125.

Vik, P. W., Cellucci, T., Jarchow, A., \& Hedt, J. (2004). Cognitive impairment in substance abuse. Psychiatric Clinics of North America, 27(1), 97-109.

Walsh, C., MacMillan, H. L., \& Jamieson, E. (2003). The relationship between parental substance abuse and child maltreatment: Findings from the Ontario Health Supplement. Child Abuse \& Neglect, 27(12), 1409-1425.

Wechsler, D. (1999). Wechsler abbreviated scale of intelligence: Psychological Corporation.

Wechsler, D. (2014). Wechsler Adult Intelligence Scale-Fourth Edition (WAIS-IV).

Wilsnack, S. C., Vogeltanz, N. D., Klassen, A. D., \& Harris, T. R. (1997). Childhood sexual abuse and women's substance abuse: National survey findings. Journal of Studies on Alcohol, 58(3), 264271.

World Health Organization (1993). The ICD-10 classification of mental and behavioural disorders: Diagnostic criteria for research.

Wunderli, M. D., Vonmoos, M., Niedecker, S. M., Hulka, L. M., Preller, K. H., Baumgartner, M. R., . . . Eich-Höchli, D. (2016). Cognitive and emotional impairments in adults with attentiondeficit/hyperactivity disorder and cocaine use. Drug and Alcohol Dependence, 163, 92-99.

Zelazo, P. D. (2015). Executive function: Reflection, iterative reprocessing, complexity, and the developing brain. Developmental Review, 38, 55-68.

Zelazo, P. D., \& Cunningham, W. A. (2007). Executive Function: Mechanisms Underlying Emotion Regulation. 


\section{Tables}

Table 1

Descriptive Statistics of Substance Use, Parental Reflective Functioning, Performance on Cognitive Tests presented by T-scores, IQ and mental health status

\begin{tabular}{|c|c|c|c|c|c|}
\hline Variable & $\mathrm{M}$ & SD & $\%$ & $\mathrm{~N}$ & Range \\
\hline \multicolumn{6}{|l|}{ Preferred Substance ${ }^{a)}$} \\
\hline Central Stimulant & & & 37.2 & 16 & \\
\hline Opioids & & & 32.6 & 14 & \\
\hline Alcohol & & & 16.3 & 7 & \\
\hline Cannabis & & & 14.0 & 6 & \\
\hline Simultaneous use of several substances ${ }^{a)}$ & & & 86.0 & 37 & \\
\hline Injecting substances ${ }^{a)}$ & & & 51.2 & 22 & \\
\hline \multicolumn{6}{|l|}{ Overdoses in life ${ }^{\text {a) }}$} \\
\hline 0 & & & 32.6 & 14 & \\
\hline $1-5$ & & & 48.9 & 21 & \\
\hline$>5$ & & & 18.5 & 8 & \\
\hline \multicolumn{6}{|l|}{ Prescribed Medications ${ }^{\text {a) }}$} \\
\hline Medically Assisted Rehabilitation & & & 25.6 & 11 & \\
\hline Medication for ADHD & & & 9.3 & 4 & \\
\hline Other & & & 18.6 & 8 & \\
\hline \multicolumn{6}{|c|}{$\begin{array}{l}\text { Debut age of substance use and report of ever having } \\
\text { used a specific substance for intoxication }\end{array}$} \\
\hline Alcohol & 13.1 & 2.2 & 97.7 & 42 & $5-19$ \\
\hline Prescribed Medications & 18.1 & 5.8 & 86.0 & 37 & $2-36$ \\
\hline Cannabis & 16.2 & 4.4 & 97.7 & 42 & $12-36$ \\
\hline Central Stimulants & 17.8 & 4.4 & 88.4 & 38 & $14-36$ \\
\hline
\end{tabular}


Opioids

$\begin{array}{lllll}20.3 & 6.0 & 58.1 & 25 & 12-36\end{array}$

Multiple Substances

Parental Reflective Functioning ${ }^{\text {b) }}$

$\begin{array}{lllll}18.4 & 4.8 & 86.0 & 37 & 12-36\end{array}$

General RF

$2.91 \quad 1.71$

0-6

Performance on Cognitive tests

Working Memory ${ }^{\text {c) }}$

Letter-Number

$41.2 \quad 8.8$

$25-65$

Inhibition ${ }^{\text {d) }}$

$39.8 \quad 11.3$

20-65

Cognitive Flexibility ${ }^{\text {d) }}$

35.211 .4

20-63

Verbal Fluency ${ }^{\mathrm{e}}$

Letter Fluency

$48.4 \quad 11.4$

21-70

Category Fluency

$59.0 \quad 11.4$

30-80

Planning ${ }^{\text {t) }}$

Tower

$45.1 \quad 6.5$

$30-59$

$\mathrm{IQ}^{\mathrm{g})}$

Verbal IQ

$89.7 \quad 17.1$

55-127

Non-verbal IQ

$98.8 \quad 14.0$

74-132

Total IQ

$94.1 \quad 14.6$

71-125

Mental health ${ }^{\text {h) }}$

SCL-10

a) European Addiction Severity Index (Europ-ASI), $5^{\text {th }}$ edition

b) Parental Development Interview - Revised, Reflective Functioning Scale

c) Letter-Number Sequencing sub-test in the Wechsler Adult Intelligence Scale, $4^{\text {th }}$ Edition

d) Colour-Word Interference Test, Conditions 3 and 4 from Delis-Kaplan Executive Function System (D-KEFS)

e) Verbal fluency test from Delis-Kaplan Executive Function System (D-KEFS)

f) Tower Test from Delis-Kaplan Executive Function System (D-KEFS)

g) Wechsler Abbreviated Scale of Intelligence (WASI)

h) Hopkins Symptom Checklist (SCL-10) 


\section{Table 2}

Correlation coefficients between Parental Reflective Functioning (item 1), measures of Executive Functions (items 2-7), IQ (items 8-10) and mental health status (item 11)

\begin{tabular}{|c|c|c|c|c|c|c|c|c|c|c|}
\hline Functions & 1 & 2 & 3 & 4 & 5 & 6 & 7 & 8 & 9 & 10 \\
\hline 1 Reflective Functioning & & & & & & & & & & \\
\hline 2 Working memory ${ }^{b}$ & $.74 * *$ & & & & & & & & & \\
\hline 3 Inhibition $^{c)}$ & $.42 * *$ & $.72 * *$ & & & & & & & & \\
\hline 4 Cognitive Flexibility ${ }^{\mathrm{c}}$ & $.58 * *$ & $.64 * *$ & $.64 * *$ & & & & & & & \\
\hline 5 Planning d) & $.63 * *$ & $.65 * *$ & $61 * *$ & $.61 * *$ & & & & & & \\
\hline 6 Letter Fluency $^{\mathrm{e}}$ & .01 & $.34 *$ & $.44 * *$ & $.41 * *$ & .19 & & & & & \\
\hline 7 Category Fluency $^{\mathrm{e})}$ & .03 & $.39 *$ & $.42 * *$ & .22 & $.37^{*}$ & $.36^{*}$ & & & & \\
\hline 8 Verbal $\mathrm{IQ}^{\mathrm{f})}$ & $.41 * *$ & $.62 * *$ & $.45 * *$ & $.47 * *$ & $.44 * *$ & $.48 * *$ & $.38 * *$ & & & \\
\hline 9 Non-verbal IQ ${ }^{\mathrm{f}}$ & $.33 * *$ & $.60 * *$ & $.51 * *$ & $.47 * *$ & $.53 * *$ & $.46^{* *}$ & $.34 *$ & $.56 * *$ & & \\
\hline 10 Total $\mathrm{IQ}^{\mathrm{f})}$ & $.44 * *$ & $.69 * *$ & $.56 * *$ & $.55 * *$ & $.54 * *$ & $.59 * *$ & $.41 * *$ & $.90 * *$ & $.83 * *$ & \\
\hline 11. HSCL-10 ${ }^{\mathrm{g})}$ & $-.56 * *$ & $-.61 * *$ & $-.48 * *$ & $-.57 * *$ & $-.53 * *$ & -10 & -26 & -.29 & $-.38 *$ & $-.38 *$ \\
\hline
\end{tabular}
$* \mathrm{p}<.05 ., * * \mathrm{p}<.01$

a) Parental Development Interview - Revised, Reflective Functioning Scale

b) Letter-Number Sequencing sub-test from the Wechsler Adult Intelligence Scale, $4^{\text {th }}$ Edition

c) Colour-Word Interference Test, Conditions 3 and 4 from the Delis-Kaplan Executive Function System (D-KEFS)

d) Tower Test from the Delis-Kaplan Executive Function System (D-KEFS)

e) Verbal fluency test from the Delis-Kaplan Executive Function System (D-KEFS)

f) Wechsler Abbreviated Scale of Intelligence (WASI)

g) Hopkins Symptom Checklist (SCL-10) 


\section{Table 3}

Multiple regression Analyses for Executive Functioning predicting Reflective Functioning controlled for total IQ and mental health status (HSCL-10)

\begin{tabular}{|c|c|c|c|c|c|}
\hline Variable & B & SE B & $\beta$ & $\mathrm{t}$ & Sig \\
\hline Total IQ & .01 & .02 & .07 & .04 & $\mathrm{NS}$ \\
\hline HSCL-10 & -.63 & .29 & -.33 & -2.2 & * \\
\hline EF-factor & .39 & .25 & .33 & 1.6 & NS \\
\hline
\end{tabular}


Table 4

Differences in psychoactive substance use between mothers with an adequate to high Parental Reflective Functioning and mothers with a negative to low Parental Reflective Functioning; Chi square analyses

\begin{tabular}{|c|c|c|c|c|c|}
\hline \multirow[t]{2}{*}{ Substance $^{\text {b) }}$} & \multicolumn{2}{|c|}{$\begin{array}{l}\text { Adequate to High } \mathrm{RF}^{\mathrm{a})} \\
\mathrm{N}: 11\end{array}$} & \multicolumn{2}{|c|}{$\begin{array}{c}\text { Negative to Low } R^{\text {a) }} \\
\mathrm{N}: 32\end{array}$} & \multirow[t]{2}{*}{ Sig } \\
\hline & $\mathrm{N}$ & $\%$ & $\mathrm{~N}$ & $\%$ & \\
\hline Alcohol & 4 & 36.5 & 14 & 48.3 & NS \\
\hline Cannabis & 7 & 63.6 & 28 & 87.5 & NS \\
\hline Central Stimulants & 6 & 54.5 & 25 & 78.1 & NS \\
\hline Opioids & 4 & 36.4 & 16 & 50.0 & NS \\
\hline Multiple Substances & 5 & 45.5 & 27 & 84.4 & $* *$ \\
\hline
\end{tabular}

$\mathrm{N}=43, * *=\mathrm{p}<.01, *=\mathrm{p}<.05, \mathrm{~ns}=$ no significant differences.

a) Parental Development Interview - Revised, Reflective Functioning Scale

b) European Addiction Severity Index (Europ-ASI), $5^{\text {th }}$ edition 
Table 5

Differences in reported substance use debut age and age of SUD onset between average to high Parental Reflective Functioning and negative to low Parental Reflective Functioning; controlling for total IQ and mental health status (HSCL-10); Multiple Analysis of Variance (MANOVA)

\begin{tabular}{|c|c|c|c|c|c|}
\hline \multirow[b]{2}{*}{ Substance $^{\text {b) }}$} & \multicolumn{4}{|c|}{$\begin{array}{cc}{\text { Adequate-High } \mathrm{RF}^{\mathrm{a}}{ }^{-}}^{\text {Negative-Low } \mathrm{RF}^{\mathrm{a}}} \\
\mathrm{N}: 11 & \mathrm{~N}: 32\end{array}$} & \multirow[b]{2}{*}{ Sig. } \\
\hline & Mean & SD & Mean & SD & \\
\hline \multicolumn{6}{|l|}{ Debut } \\
\hline Alcohol & 14.8 & 1.9 & 12.6 & 2.1 & $* *$ \\
\hline Prescribes Medications & 23.9 & 6.1 & 16.7 & 4.9 & $* *$ \\
\hline Cannabis & 19.5 & 6.5 & 15.2 & 3.0 & $* *$ \\
\hline Central Stimulants & 20.8 & 6.6 & 16.9 & 3.1 & $*$ \\
\hline Opioids & 26.8 & 7.0 & 18.0 & 5.0 & $*$ \\
\hline Multiple Substances & 17.0 & 8.1 & 15.2 & 6.7 & NS \\
\hline \multicolumn{6}{|l|}{ SUD } \\
\hline Alcohol & 24.8 & 7.9 & 15.4 & 2.2 & $* *$ \\
\hline Prescribed Medications & 24.0 & 5.5 & 19.0 & 3.4 & $* *$ \\
\hline Cannabis & 22.6 & 7.0 & 17.8 & 3.5 & $*$ \\
\hline Central Stimulants & 21.3 & 7.4 & 18.5 & 3.2 & NS \\
\hline Opioids & 27.3 & 6.3 & 18.8 & 3.5 & $* *$ \\
\hline Multiple Substances & 23.3 & 7.1 & 18.4 & 3.1 & $*$ \\
\hline
\end{tabular}
$\mathrm{N}=43, * *=\mathrm{p}<.01, *=\mathrm{p}<.05, \mathrm{~ns}=$ no significant differences.

a) Parental Development Interview - Revised, Reflective Functioning Scale

b) European Addiction Severity Index (Europ-ASI), $5^{\text {th }}$ edition 
Table 6

Differences in Executive Functions between mothers with adequate to high Parental Reflective Functioning and mothers with a negative to low Parental Reflective Functioning controlling for total IQ and mental health status (HSCL-10); Multiple Analysis of Variance (MANOVA)

\begin{tabular}{lccccc}
\hline & \multicolumn{3}{c}{$\begin{array}{c}\text { Adeqate-High PRF } \\
\text { N:11 }\end{array}$} & \multicolumn{3}{c}{$\begin{array}{c}\text { Negative-Low PRF } \\
\text { N:32 }\end{array}$} \\
\hline Variable & Mean & SD & Mean & SD & Sig. \\
\hline & & & & & \\
Working Memory $^{\text {b) }}$ & 49.1 & 9.3 & 38.4 & 6.9 & $*$ \\
Inhibition $^{\text {c) }}$ & 46.2 & 12.6 & 37.6 & 10.2 & NS \\
Cognitive Flexibility $^{\text {c) }}$ & 44.7 & 9.8 & 31.9 & 10.1 & $*$ \\
Letter Fluency $^{\text {d) }}$ & 48.6 & 11.3 & 48.3 & 11.6 & NS \\
Category Fluency $^{\text {d) }}$ & 60.3 & 8.6 & 58.6 & 12.3 & NS \\
Planning $^{\text {e) }}$ & 50.6 & 5.4 & 43.2 & 5.7 & $*$ \\
\hline
\end{tabular}

$\mathrm{N}=43, * *=\mathrm{p}<.01, *=\mathrm{p}<.05, \mathrm{~ns}=$ no significant differences.

a) Parental Development Interview - Revised, Reflective Functioning Scale

b) Letter-Number Sequencing sub-test from the Wechsler Adult Intelligence Scale, $4^{\text {th }}$ Edition

c) Colour-Word Interference Test, Conditions 3 and 4 from the Delis-Kaplan Executive Function System (D-KEFS)

d) Verbal fluency test from the Delis-Kaplan Executive Function System (D-KEFS)

e) Tower Test from the Delis-Kaplan Executive Function System (D-KEFS) 
